\title{
NOTE ON INTERNATIONAL COMPARISON OF X-RAY STANDARDS
}

\author{
By Lauriston S. Taylor
}

A recent paper ${ }^{1}$ gave a description of comparisons of the Bureau of Standards X-ray ionization standard with that of the National Physical Laboratory, Physikalisch-technische Reichsanstalt, and Le Service d'Etalonnage de l'Hôpital St. Antoine. In these comparisons it was necessary in all cases to make corrections for the absorption of $\mathrm{X}$ rays in air, for which absorption coefficients were obtained by extrapolation from available data. These coefficients are, as pointed out, uncertain.

Unfortunately, corrections for this paper, suggested by Doctor Kaye, were received after it was too late to insert them. He informs us that their recent determinations of the air absorption correction under the conditions used in the comparisons gives values somewhat different from those used in the published paper. For $110 \mathrm{kv}$ unfiltered radiation Doctor Kaye finds a correction of 2.2 per cent as against 1.5 per cent used in the published paper. For $143 \mathrm{kv}, 1.4$ $\mathrm{mm}$ copper, his correction agreed with the published value. Applying the first correction raises the values of the N. P. L. determination by approximately 0.7 per cent.

When Kaye's values are used, column 11, Table 3 of the published paper becomes:

Average difference of intact systems.
Corrected for compensator differences.
Average difference when using the same diaphragms
Corrected for compensator differences.

The resulting N. P. L. values for the magnitude of the roentgen, as given in Table 9, column 4, are:

1.005 when corrected for diaphragm differences.

.996 when using the same diaphragm on both chambers.

1.0005 when averaging all readings taken.

We would also call attention to an error, page 16, line 3 under Table 3. The sentence should read: "Runs 1 and 3 are straightforward comparisons; run 2 was made with the tube diaphragm increased in diameter from 12 to $30 \mathrm{~mm}$; * * *."

Washington, January 8, 1932.

1 L. S. Taylor, B. S. Jour. Research, vol. 8 (RP397), pp. 9-24, 1932. 